\section{¿Qué tan ético es "vestir verde"?}

\author{
Mag. Natalia Sofía Tenaglia ${ }^{(1)}$
}

Resumen: Los consumidores de ropa, calzado y bolsos han mostrado, en los últimos años, una creciente preocupación por el cuidado del medio ambiente. Al elegir una prenda, los consumidores de hoy exigen que los productos que compran sean sostenibles. Los desarrollos biotecnológicos en la industria de la moda han desarrollado textiles altamente sostenibles y estas tecnologías están trasladando las fuentes de materias primas de la granja al laboratorio. Sin embargo, las nuevas tecnologías para desarrollar textiles sostenibles tienen la capacidad de ser beneficiosas para el medio ambiente; pero a su vez, enfrentamos desafíos éticos desde el punto de vista social debido a su potencial para aumentar la brecha tecnológica entre países. Por lo tanto, promover la colaboración internacional con los países en desarrollo ayudaría a las marcas en la industria de la moda a ser no solo sostenibles con respecto al medio ambiente, pero también social y éticamente responsable.

Palabras clave: brecha tecnológica - desarrollo biotecnológico - etica - responsabilidad nuevos materiales.

[Resúmenes en inglés y portugués en las páginas 63-64]

(1) Abogada argentina, graduada con honores en la Universidad de Buenos Aires (UBA) y Magister en Derecho Internacional en ISDE-España. Natalia tiene amplia experiencia en Derecho Corporativo e Internacional. Fue Profesora en la Facultad de Derecho de la UBA, Directora de Empresas y Coordinadora de Propiedad Intelectual para el Estado Nacional Argentino. Actualmente es candidata a LLM en Fashion Law en la Universidad de Fordham de Nueva York.

Las nuevas tecnologías para desarrollar textiles sostenibles tienen la capacidad de ser beneficiosas desde el punto de vista ambiental; pero a su vez nos enfrentan a desafíos éticos desde el punto de vista social debido a su potencial para incrementar la brecha tecnológica entre países. 


\section{Introducción}

Los consumidores de productos de indumentaria, calzado y bolsos de mano, han mostrado en los últimos años una creciente preocupación por el cuidado del medio ambiente y el consumo responsable. Al momento de elegir una prenda, los compradores de hoy, exigen que los productos que adquieran sean sostenibles.

La concientización por el consumo responsable se incrementó, a nivel mundial, a partir del año 2013 como consecuencia del trágico y desafortunado evento conocido como el colapso del Rana Plaza en Bangladesh. El edificio que alojaba fábricas de ropa se derrumbó a causa del mal estado de mantenimiento y la falta de medidas de seguridad. Más de mil personas murieron y más de dos mil resultaron heridas, entre ellos menores de edad. Estas fábricas producían ropa para marcas internacionales como Mango, El Corte Inglés, Benetton y Primark, entre otras. Ante semejante tragedia, los ojos del mundo arduamente comenzaron a reclamar conciencia social a las empresas para vestirnos éticamente.

¿Quién hizo mi ropa? Continúan reclamando algunos movimientos globales que nacieron a raíz de la tragedia de Rana Plaza, y exigen una industria de la moda más justa, segura y transparente. Actualmente, los consumidores actuales exigen transparencia en toda la cadena de producción. "Fashion Revolution" afirma: "Los esfuerzos de colaboración de toda la cadena de valor, desde el agricultor hasta el consumidor, son la única forma de transformar la industria en cualquier aspecto de viabilidad". ${ }^{1}$ Los consumidores no sólo esperan que las marcas sean ambientalmente sustentables, sino también socialmente responsables. Muchas de las nuevas tecnologías para producir textiles sostenibles están siendo desarrolladas en laboratorios, en lugar de en las tradicionales granjas de agricultores. Estas innovaciones en materia tecnológica, especialmente el uso de la biotecnología en la industria textil, nos enfrenta a nuevos cuestionamientos y desafíos éticos, legales y sociales.

\section{La preocupación internacional}

“En 2015, la ONU aprobó la Agenda 2030 para el Desarrollo Sostenible, una oportunidad para que los países y sus sociedades se embarquen en un nuevo camino para mejorar la vida de todos, sin dejar a nadie atrás. La Agenda tiene 17 Objetivos de Desarrollo Sostenible, que incluyen desde la eliminación de pobreza a la lucha contra el cambio climático". ${ }^{2}$ En este contexto de preocupación internacional, "la moda es una de las industrias más contaminantes. Según un estudio del Programa de las Naciones Unidas para el Medio Ambiente realizado en noviembre del 2019, la industria produce el 20\% de las aguas residuales mundiales y el $10 \%$ de las emisiones mundiales de carbono, más que todos los vuelos internacionales y el transporte marítimo combinado. El teñido de textiles es el segundo contaminador de agua a nivel mundial, y se necesitan alrededor de 2,000 galones de agua (más de 7.500 litros) para hacer un par de jeans típicos, según el estudio." ${ }^{3}$ En otras palabras, la industria textil es la segunda más contaminante después de la petrolera. Conforme los datos de aa Conferencia de las Naciones Unidas sobre Comercio y Desarrollo (CNUCYD) el rubro indumentaria utiliza cada año 93.000 millones de metros cúbicos de 
agua. Este volumen de agua es suficiente para satisfacer las necesidades de cinco millones de personas. Además, la CNUCYD informa que cada año se tiran al mar medio millón de toneladas de microfibra, el equivalente a 3 millones de barriles de petróleo. ${ }^{4}$

Ante este panorama, en el año 2019 las empresas de la industria textil y de la moda (prêtà-porter, deporte, estilo de vida y lujo) firmaron en Francia el Pacto de la Moda -conocido mundialmente como el Fashion Pact G7-. Lanzado como una misión dada al presidente y CEO de Kering, François-Henri Pinault por el presidente francés, Emmanuel Macron, el Pacto de la Moda se presentó a los Jefes de Estado en la Cumbre del G7 en Biarritz. Entre los signatarios del Pacto se encuentran reconocidas marcas como: Adidas, Burberry, Carrefour, Chanel, El Corte Inglés, Ermenegildo Zegna, Galerias Lafayette, Gap Inc. H\&M Group, Hermes, Inditex, Karl Lagerfeld, Mango, Nike, Prada, Ralph Lauren, PVH Corp., Stella McCartney, entre otros. ${ }^{5}$

A través de este Pacto, los grandes de la industria se alinearon con los objetivos de desarrollo sostenible de la ONU, en una clara demostración de la voluntad de la comunidad de la moda de ser parte de la solución ambiental y no ser parte del problema.

El pacto establece tres pilares como objetivos medioambientales: clima, biodiversidad y océanos. Es decir, la detención del calentamiento global, la restauración de la biodiversidad y la protección de los océanos. Según Forbes: "El pacto admite que una gran parte no abordada del impacto ambiental de la industria radica en la "primera milla" de las cadenas de suministro de moda, como a nivel de granja y donde se obtienen las materias primas". ${ }^{6}$ Así, para combatir la crisis climática, los signatarios de las marcas de moda se comprometen a implementar "objetivos basados en la ciencia", incluido el abastecimiento sostenible de materias primas claves. ${ }^{7}$

El desarrollo tecnológico es un medio importante para alcanzar objetivos sostenibles. Por ello, la innovación tecnológica para el desarrollo de textiles que puedan facilitar su disposición final como desechos no contaminantes, es un gran paso en términos sostenibles.

Nuevos tejidos biodegradables se están cultivando dentro de laboratorios, y algunos de estos tejidos tiene el potencial de reemplazar la materia prima tradicional de la granja; pero los avances tecnológicos en materia textil para proteger el medio ambiente, pueden tener consecuencias sociales no deseadas -impactando especialmente en los países proveedores de la materia prima tradicional. Así, las prendas que se comiencen a diseñar con textiles cultivadas a través de la biotecnología, serán sostenibles pero sólo parcialmente, si no se considera también el factor social al momento de la investigación y desarrollo. En la actualidad, los consumidores no son del todo conscientes del impacto social qué pueden tener estas nuevas tecnologías; a pesar de que las Naciones Unidas ha comenzado a plantear el problema.

En tal sentido, el Consejo Económico y Social de las Naciones Unidas en su informe del año 2018 sostuvo que: "las tecnologías de vanguardia ofrecen un inmenso potencial para implementar la Agenda 2030 para el Desarrollo Sostenible, porque al usarlas, se promueve la sostenibilidad ambiental. Estas tecnologías también conllevan riesgos significativos en términos de desempleo, subempleo y aumento de las desigualdades de ingresos y riqueza, al tiempo que plantea nuevas preocupaciones éticas y morales".

El informe del Consejo Económico y Social del año 2019 enfatiza que los cambios tecnológicos rara vez son inofensivos. Por el contrario, en pasadas oportunidades han contribuido 
a aumentar la desigualdad de ingresos entre países y regiones. Por lo tanto, para alcanzar las metas 2030 sin "dejar a nadie atrás", es esencial establecer estándares éticos. "Sin políticas de ciencia, tecnología e innovación adecuadas, las tecnologías, ya sean antiguas o nuevas, tienen pocas probabilidades de contribuir al desarrollo mundial. Para avanzar es necesario un entorno que fomente el aprendizaje y la innovación y permita construir y gestionar sistemas de innovación eficaces". ${ }^{\prime 9}$

La industria de la moda no es ajena a esta innovación tecnológica y sus consecuencias. Sin embargo, para alcanzar el objetivo de ser una industria transparente y sostenible, debemos evitar que en pos de la sostenibilidad se amplíe la brecha tecnológica entre países. Debemos ser realistas sobre el impacto social que estos objetivos y tecnologías "verdes" tendrían en los países en desarrollo, especialmente en aquellos que actualmente proporcionan materias primas que serían reemplazadas por las materias primas cultivas en laboratorios.

Las innovaciones textiles mencionadas a continuación son ejemplos ilustrativos de algunos de los desarrollos biotecnológicos actuales en la industria de la moda. Avances sobre el cuero y otros tejidos cultivados, trasladan la fuente de materias primas de la granja al laboratorio.

\section{Tech Fashion}

La biotecnología ha comenzado a tener un rol muy importante en el mundo textil para alcanzar los ambiciosos objetivos de sostenibilidad ambiental. Esta nueva ola tecnológica que utiliza organismos vivos en laboratorios para cultivar tejidos textiles, si bien actualmente se encuentra en etapa de prototipos, está creciendo rápidamente. Las grandes marcas y casas de diseño trabajan con científicos para desarrollar estas tecnologías y lanzarlas al mercado.

En materia de cuero cultivado en laboratorios, una gran referente es Stella McCartney. En su sitio web podemos leer: "Como marca vegetariana, nunca usamos cuero, piel, pieles o plumas. Al adoptar esta postura, estamos demostrando que es posible crear productos hermosos y lujosos que son mejores para todos: animales, personas y el medio ambiente". McCartney Lanzó su etiqueta homónima en 2001 sosteniendo estos principios "vegetarianos". "Su piel sintética tiene credenciales ecológicas: el revestimiento de alter-nappa está hecho con un 60 por ciento de aceite vegetal; sus poliuretanos son a base de agua y libres de solventes, lo que significa que son menos intensivos en energía y agua y están hechos sin solventes tóxicos". Su sitio web cita una estadística de Environmental Profit and Loss (EP\&L) que "usar poliéster reciclado en lugar de piel de becerro brasileña, por ejemplo, crea un impacto ambiental 24 veces menor". Pero incluso ella ha tenido que reconocer "que en las alternativas sintéticas el uso no está exento de preocupaciones medioambientales". Por eso, está estudiando el cuero cultivado en laboratorio como alternativa". ${ }^{10}$

Stella menciona en su website: "Estamos entusiasmados por el futuro de las pieles libres de crueldad. Una oportunidad que estamos explorando actualmente es el cuero cultivado en laboratorio. Lo que puede haber parecido imposible hace solo unos años se está convir- 
tiendo rápidamente en una realidad. Como empresa moderna, nosotros queremos llevar estas increíbles hazañas de diseño a la industria de la moda y allanar el camino hacia un enfoque más progresivo de los materiales". ${ }^{11}$ En este caso, una vez que el cuero cultivado en laboratorios alcance un nivel de producción comercial, podría tener un impacto en las industrias tradicionales del cuero (incluido el cuero sintético), afectando el número de exportaciones de cuero desde los países en desarrollo, sumado a la carencia de las tecnologías para competir con la nueva industria de cuero cultivado.

Además, McCartney también ha diseñado conjuntos hechos con seda inspirada en las arañas. La diseñadora "proporcionó un vestido dorado de seda fabricada en laboratorio para la exposición del Museo de Arte Moderno 'Artículo: ¿Es moderna la moda?' También presentó un traje y pantalón marrón chocolate en el backstage de su show de primavera de 2018 durante la Semana de la Moda de París. 'No lo han perfeccionado por completo, pero es una seda; Es literalmente una seda, pero tiene una textura ligeramente diferente a la seda que usamos habitualmente', dijo Claire Bergkamp, directora de sostenibilidad y comercio ético de la marca Stella McCartney." ${ }^{12}$ La marca ha firmado un acuerdo de asociación a largo plazo con Bolt Threads, la compañía de California que desarrolló el material Microsilk..$^{13}$

Otro avance en tecnología textil es, por ejemplo, el desarrollo de seda de araña a partir de la fermentación de bacterias. AMSilk, una empresa con sede en Alemania, utiliza bacterias genéticamente modificadas para solucionar el problema de la imposibilidad de cultivar arañas a escala industrial. Dentro de los biorreactores de fermentación, la bacteria produce proteína de seda de araña, que luego se convierte en fibras, creando un nuevo material con propiedades únicas". "La compañía está trabajando en varios otros productos que utilizan fibras de seda de araña, incluidas las zapatillas de deporte biodegradables para Adidas". ${ }^{14}$

El CEO de AMSilkKlein, Jens Klein, explicó: "Por un lado, los consumidores quieren productos con mejores propiedades de rendimiento y, por otro, exigen materiales y métodos de producción más sostenibles. Los materiales tradicionales no pueden satisfacer ambas demandas, pero los materiales biofabricados sí". ${ }^{15}$

Otro textil innovador se cultiva a partir de hongos. La firma holandesa NEFFA ha creado un textil creativo que se cultiva a partir de las raíces de los hongos. Los hongos crecen en discos que luego se unen para crear ropa personalizada sin costuras. Aniela Hoitink, la fundadora de NEFA, dijo: "A medida que omitimos los pasos de hilar, tejer telas, cortar patrones y coser prendas, no solo estamos reduciendo los desechos durante la fase de producción, sino también recursos como el agua, las tierras de cultivo y el transporte". ${ }^{16}$ Por otro lado, Andras Forgacs es el cofundador y director ejecutivo de Modern Meadow, una firma de biofabricación que creó Zoa, un material inspirado en el cuero camaleónico cultivado en laboratorio, hecho con su proteína de colágeno diseñada. Zoa es un material "altamente adaptable" y moldeable, que se puede combinar fácilmente con otros materiales y adaptarse a cualquier forma o textura. Forgacs ha mencionado que: "Necesitamos actuar hoy para encontrar soluciones que funcionen mejor para nuestro planeta. Al ritmo que vamos, vamos a agotar los recursos naturales de la tierra más rápido de lo que podemos consumirlos. Necesitamos reducir el desperdicio y la producción de productos químicos nocivos, materiales y artículos que acaban en nuestros vertederos. En Modern Meadow, 
creemos que la biofabricación libera el poder de la naturaleza para inspirar nuevos diseños para un planeta más saludable. Nuestro proceso pionero todavía está en desarrollo, pero anticipamos que tiene ventajas sobre la producción ganadera en términos de tierra, uso de agua y emisiones de $\mathrm{CO} 2$. También utilizamos el análisis del ciclo de vida para guiar nuestro desarrollo y garantizar que nuestro proceso esté optimizado para ser lo más eficiente posible y lo más ecológico posible ". ${ }^{17}$

Además de los mencionados desarrollos, "se espera que las marcas anuncien asociaciones con empresas que han descubierto formas de hacer cuero sin vacas, seda sin gusanos, pieles sin animales y telas con desechos reciclados". ${ }^{18}$ En efecto, además de la asociación entre McCartney y Adidas, "Salvatore Ferragamo ha estado vendiendo bufandas hechas de fibras de naranjas". También la compañía norteamericana de ropa deportiva North Face se ha asociado a la compañía japonesa Spiber, para desarrollar tecnologías para crear seda sustentable ${ }^{19}$. Así, la lista de marcas de indumentaria que invierten fondos en el desarrollo de textiles sostenibles sigue creciendo.

\section{Innovación con estándares éticos}

El Consejo Económico y Social de las Naciones Unidas sostiene que los rápidos cambios tecnológicos seguramente tendrán efectos transformadores favoreciendo el desarrollo sostenible, pero también esos efectos podrían tener efectos disruptivos que en lugar de favorecer, frustren el logro de los Objetivos de Desarrollo Sostenible. "Aunque la aplicación de tecnologías nuevas y emergentes representa una oportunidad de acelerar el avance hacia el logro de los Objetivos de Desarrollo Sostenible, los cambios tecnológicos rápidos también pueden perturbar los mercados y las economías, acentuar la brecha social y plantear problemas de carácter normativo". ${ }^{20}$

"El cambio tecnológico rápido puede perpetuar las diferencias que existen tanto dentro de los países como entre ellos, así como entre las mujeres y los hombres, las poblaciones rurales y urbanas y las comunidades pobres y ricas." ${ }^{21}$

El Consejo Económico y Social de las Naciones Unidas declaró que, dados los rápidos cambios tecnológicos (como en biotecnología), es necesario armonizar y equilibrar la eficiencia y la rentabilidad con las normas éticas y las consideraciones de equidad.

Las respuestas a estos desafíos sólo pueden provenir de iniciativas coordinadas. Los progresos tecnológicos no han sido homogéneos en todos los países. En gran medida, las innovaciones tecnológicas se concentran en un pequeño grupo de países desarrollados y en menor medida en algunos países en desarrollo. Por esta razón, la cooperación internacional entre países en materia de investigación y desarrollo, puede ser un camino hacia una colaboración más ética en el desarrollo de estas tecnologías en la industria textil. "Mediante la cooperación a escala regional e internacional y entre múltiples interesados, la comunidad internacional puede contribuir a las iniciativas encaminadas a poner el cambio tecnológico rápido al servicio del desarrollo sostenible y evitar que acentúe las brechas, las desigualdades socioeconómicas y la degradación del medio ambiente".22

La aplicación de estándares éticos de colaboración para ser socialmente responsables, 
debe comenzar desde la etapa de investigación y desarrollo a través de la cooperación global. La cooperación internacional en Investigación y Desarrollo ha sido efectiva en diferentes campos tecnológicos, como la defensa y la medicina. Los textiles sostenibles no deberían ser la excepción. En el caso puntual de la cooperación tecnológica con America Latina, estas economías en desarrollo tienen la ventaja de contar con excelentes recursos humanos y grandes espacios disponibles para instalar laboratorios. Sin embargo, muchos de estos países, no tienen la capacidad fiscal para alentar y apoyar los desarrollos tecnológicos. Las economías desarrolladas que sí tienen la capacidad fiscal podrían contribuir con los fondos y llevar a cabo sus proyectos de Investigación y Desarrollo en países en desarrollo con recursos humanos de y en estos países. De este modo el beneficio es recíproco, el país desarrollado logra investigar y desarrollar tecnologías a menores costos, y simultáneamente, el país en desarrollo también obtiene beneficios, ya que la capacidad aprendida por sus científicos y los acuerdos de transferencia de tecnología brindarían capacidades únicas que ayuden al desarrollo económico y social de esas comunidades. En el contexto de las Naciones Unidas y otros acuerdos multilaterales, la transferencia de tecnología a menudo se ha considerado como un proceso de "adquisición" a través del cual los países en desarrollo intentan obtener acceso a productos y conocimientos importados del mundo desarrollado.

Otros acuerdos de cooperación internacional más ambiciosos apuntan a compartir los derechos de propiedad intelectual del desarrollo tecnológico. Este tipo de colaboración alcanzaría un nivel aún más alto de cooperación y compromiso ético para reducir el impacto social y la brecha tecnológica. Mediante este tipo de acuerdos, las empresas compartirían los beneficios de las patentes con quienes contribuyeron a su desarrollo. Las economías afectadas se beneficiarían al acceder a nuevas tecnologías que luego servirían de puntapié inicial para el desarrollo de nuevos productos.

Aspirando a niveles de colaboración éticamente más ambiciosos, el Consejo Económico y Social ha dicho que: "Puesto que se ha demostrado que la rigidez del régimen mundial de derechos de propiedad intelectual ha hecho que sea cada vez más difícil transferir tecnologías, la flexibilidad jurídica e institucional se ha convertido en un prerrequisito indispensable. Con el fin de aliviar esa rigidez se precisa una estrategia pluridimensional que incorpore criterios flexibles para definir las normas nacionales de patentabilidad, mantener o incluso ampliar las exenciones de patentes de los países en desarrollo, aumentar la viabilidad y la eficacia de los procesos de concesión de licencias obligatorias, y asegurar el acceso inclusivo a los datos tecnológicos. Además, urge crear una entidad internacional que determine un conjunto de tecnologías de vanguardia esenciales para conseguir el desarrollo sostenible. Dichas tecnologías esenciales deberían declararse bienes públicos mundiales y ponerse a disposición de las sociedades y las comunidades por consenso internacional, lo que sería un reflejo del respeto de la responsabilidad común pero diferenciada de todos los interesados". ${ }^{23}$ 


\section{Conclusión}

Los desafíos ambientales que actualmente estamos enfrentando, han llevado a un cambio de paradigma en las industrias textiles, indumentaria, calzado y bolsos de mano. En el afán de alcanzar las metas ambientales y satisfacer a los consumidores conscientes de la necesidad de vestir prendas sustentables, las marcas de moda han rápidamente buscado asociaciones tecnológicas para el desarrollo de textiles sustentables, dando lugar al reemplazo de las materias primas obtenidas de las granjas, a las materias primas cultivadas en laboratorios.

Sin embargo, los rápidos desarrollos tecnológicos si bien tienen un fin novel, pueden causar un impacto social negativo incrementando la brecha tecnológica entre las comunidades.

El establecimiento de estándares éticos de colaboración internacional (integrando aspectos sociales y no solo ambientales a los desarrollos tecnológicos) le otorgaría a la industria de la moda una contribución más significativa y auténtica para alcanzar los objetivos globales de sustentabilidad.

Por ello, promover la colaboración tecnológica internacional con los países en desarrollo, ayudaría a las marcas de la industria de la moda a ser sostenibles no sólo respecto los asuntos ambientales, sino también a ser social y éticamente responsables.

"Dale un pescado a un hombre y lo alimentarás por un día.

Dale a un hombre una caña de pescar, y él se alimenta a sí mismo

y a su familia mientras dure la caña.

Ayudar a un hombre a desarrollar el conocimiento y los medios para mejorar la caña de pescar y diseñar y producir otros nuevos, y puede alimentarse a sí mismo y a su sociedad en los años venideros."

Una nueva versión de un viejo proverbio.

\section{Notas y Referencias Bibliográficas}

1. https://www.fashionrevolution.org/about/

2. https://www.forbes.com/sites/andriacheng/2019/08/23/major-fashion-companiessign-pact-vowing-to-reduce-industrys-environmental-impact/\#5bc7914db188

3. https://news.un.org/es/story/2019/04/1454161

4. Cf. supra

5. https://thefashionpact.org/?lang=en

6. https://www.forbes.com/sites/andriacheng/2019/08/23/major-fashion-companiessign-pact-vowing-to-reduce-industrys-environmental-impact/\#5bc7914db188 7. https://www.nytimes.com/2019/08/23/fashion/environment-crisis-pact-kering-g7. html 
8. https://www.un.org/development/desa/dpad/wp-content/uploads/sites/45/ WESS2018-overview_sp.pdf

9. https://unctad.org/meetings/en/SessionalDocuments/ecn162019d2_en.pdf

10. https://www.vogue.co.uk/article/vegan-leather-sustainability-debate-2019

11. https://www.stellamccartney.com/experience/en/sustainability/themes/materialsand-innovation/vegetarian-leather/

12. https://www.nytimes.com/2017/11/12/style/alternative-fabrics-sustainability-recycling.html

13. (https://www.nytimes.com/2017/11/12/style/alternative-fabrics-sustainability-recycling.html)

14. https://www.labiotech.eu/features/biofabrication-fashion-industry/

15. Cf. supra

16. Cf. supra

17. https://wwd.com/business-news/business-features/fabrics-the-future-1202935732/

18. https://www.nytimes.com/2017/11/12/style/alternative-fabrics-sustainability-recycling.html

19. Cf. supra

20. https://www.un.org/development/desa/dpad/wp-content/uploads/sites/45/

WESS2018-overview_sp.pdf “El estudio de la orientación, la distribución y la diversidad de las vías de innovación en el contexto de los Objetivos de Desarrollo Sostenible, podría permitir que los encargados de la formulación de políticas promovieran nuevas formas de innovación que eviten los problemas económicos, sociales y ambientales causados por los avances tecnológicos en el pasado".

21. Cf. supra "Los países que desean cruzar la frontera tecnológica tienden a saltar etapas principalmente mediante la adopción de tecnologías, y no mediante el desarrollo de tecnologías nuevas. Sin embargo, las políticas de innovación pueden ayudar a los países en desarrollo a fomentar y facilitar la implantación de tecnologías de frontera y la adaptación de estas a sus propias necesidades, favoreciendo el desarrollo sostenible".

22. Cf. supra

23. Cf. Supra

\begin{abstract}
Consumers of clothing, footwear and handbags have shown, in recent years, a growing concern for the care of the environment. When choosing a garment, today's consumers demand that the products they purchase be sustainable. Biotechnological developments in the fashion industry have developed highly sustainable textiles and these technologies are moving the sources of raw materials from the farm to the laboratory. However, new technologies for developing sustainable textiles have the ability to be environmentally beneficial; but in turn we face ethical challenges from the social point of view due to its potential to increase the technological gap between countries. Therefore, promoting international collaboration with developing countries would help brands in the fashion industry to be not only sustainable with respect to environment, but also social and ethically responsible.
\end{abstract}


Keywords: technological gap - biotechnological development - ethics - responsibility new materials.

Resumo: Consumidores de roupas, calçados e bolsas têm demonstrado, nos últimos anos, uma crescente preocupação com o cuidado com o meio ambiente. Ao escolher uma peça, os consumidores de hoje exigem que os produtos que compram sejam sustentáveis. Os desenvolvimentos biotecnológicos na indústria da moda desenvolveram tecidos altamente sustentáveis e essas tecnologias estão transferindo as fontes de matérias-primas da fazenda para o laboratório. No entanto, novas tecnologias para o desenvolvimento de têxteis sustentáveis têm a capacidade de ser ambientalmente benéficas; mas, por sua vez, enfrentamos desafios éticos do ponto de vista social, devido ao seu potencial de aumentar a lacuna tecnológica entre os países. Portanto, promover a colaboração internacional com os países em desenvolvimento ajudaria as marcas da indústria da moda a não apenas serem sustentáveis em relação ao meio ambiente, mas também social e eticamente responsável.

Palavras chave: lacuna tecnológica - desenvolvimento biotecnológico - ética - responsabilidade - novos materiais.

[Las traducciones de los abstracts fueron supervisadas por el autor de cada artículo] 